\title{
Proximate Evaluation of Organic Pollutants in Onion Plants Cultivated Along the Bank of River Jakara Kano State of Nigeria
}

\author{
Ambrose Ekevwe, Isaac Aloba, Garba Mahdi Doka \\ Department of Chemistry, School of Science Education, Federal College of Education (Technical) Bichi, Kano State, Nigeria
}

Email address:

upambrose@yahoo.com (A. Ekevwe)

\section{To cite this article:}

Ambrose Ekevwe, Isaac Aloba,Garba Mahdi Doka. Proximate Evaluation of Organic Pollutants in Onion Plants Cultivated Along the Bank of River Jakara Kano State of Nigeria. Advances in Biochemistry. Vol. 5, No. 3, 2017, pp. 41-46. doi: 10.11648/j.ab.20170503.12

Received: April 18, 2017; Accepted: May 6, 2017; Published: June 27, 2017

\begin{abstract}
The paper gave result findings for organic pollutants in onion plants cultivated along the bank of River Jakara Kano State. Samples of onions were purchased and harvested in farms cultivated in the banks of the aforementioned Rivers. Samples of onions were treated and analyzed in National Research and Institute for Chemical Technology (NARICT) Laboratory Zaria, Nigeria. Onion root samples analyzed has six (6) groups of organic pollutantsdetected with various percentage values. They include alkane (decane $10.6 \%$, undecane $9.2 \%$, dimethyl undecane, 2.3\%, trimethyldecane 2.2\%); alkyne (octadecyne, 1.9\%); arene (aromadendrene, 2.3\%); alkanol (phytol, $1.0 \%$ ); fatty acid (hexadecanoic acid, $1.34 \%$, linolenic acid, 1.7\%); organosulphur (diphenyl cyclo propyl phenyl sulphoxide, $3.1 \%$ ). While the onion control samples (collected from river Watari without activity) analyzed, gave one group of organic pollutants that is alkane group, they include docane $(9.0 \%, 20.1 \%)$, methyl docane $(9.2 \%, 12.8 \%)$, dodecane $(4.0 \%, 8.6 \%)$, trimethylundecane $(10.4 \%, 2.6 \%)$, octacosane $(2.5 \%, 1.4 \%)$ and hexadecane $(0.7 \%, 1.7 \%)$. The result of this study indicates that all the samples collected, examined and analyzed for onions (with exception of control samples) have percentage (\%) values greater than threshold level recommended by World Health Organization (WHO) and National Environmental Standards and Regulations Enforcement Agency (NESREA), which is unsafe for human consumption.
\end{abstract}

Keywords: Organic, Pollutant, Threshold

\section{Introduction}

Organic compounds are compounds that contain carbon, usually in combination with elements such as hydrogen, oxygen, nitrogen and sulphur. It is also compounds that consist of long bonds, usually made up of carbon and other elements mostly from living origin. Organic pollution is the term used when large quantity of organic compounds (pollutants) from domestic activities, industrial operations and agricultural processes are discharged into air, soil, water or even plants.

Surface water such as lakes, streams and rivers are important sources of water for various human activities, including agricultural production. These waters are also used as an avenue for dumping wastes which consist of inorganic, organic and microbial pollutants. But, heavy organic concentrations in soil and water are associated with biological and geochemical cycles and are influenced by anthropogenic activities such as agricultural practices, industrial activities and waste disposal methods. Contamination and subsequent pollution of the environment by organic pollutant have become a global concern due to their distribution and effect on the ecosystem.

Researchers like [1] \& [2] among others have shown that some common vegetables are capable of accumulating high level of metals and organic compounds from the soil. Certain species of Brassica (cabbage) are hyperaccumulators of organic compounds and heavy metals in the edible tissues [3]. Therefore, people could be at risk of 
adverse health effects of consuming common vegetable cultivated in contaminated soil and water.

The population mostly affected by organic pollutant toxicity is pregnant women, very young children and aged human [2] \& [4]. Neurological disorders, central nervous system destruction and cancers of various body organs are also organic pollutants effects. Low birth weight and mental retardation of newly born children have been reported in some pregnant women ingested with organic chemicals [2] \& [5]. Hence, it is important to keep constant monitoring of vegetable plants especially those cultivated and preserved by organic substances.

\subsection{Justification for the Research}

River Jakara got its name from one of the early historic settlements near Dala in the core of Kano city. It geographical characteristics falls between latitudes ' $8^{\circ} 30^{\prime} \mathrm{N}$ in Wasai village and $8^{0} 50^{\prime} \mathrm{N}$ in Yadai village and longitudinally falls between ' $12^{\circ} 5$ ' $\mathrm{E}$ and ' $12^{\circ}{ }^{\circ} 19^{\prime} \mathrm{E}$. Generally, the entire field along River Jakara is an area used throughout the dry season (over seven months) for cultivation of variety of vegetable crops, which include cabbage, garden egg, carrot, lettuce, spinach, onions, tomatoes, water leaves among others. These vegetables are important part of human food and people eat them raw or cooked. The river receives waste water from industrial, domestic and agricultural activities. Literature research revealed paucity on studies of organic pollutants in vegetables cultivated in this area. That is why this research work is directed to investigate the organic pollutants in plant cultivated in this area using onion as its case study.

\subsection{Aim and Objective of the Project}

1. To detect the presence of organic pollutants of onion plants cultivated in the river.

2. To describe the health implication / toxicity of organic pollutants discovered in man.

3. To compare the results obtained with CONTROL samples of similar vegetable plant.

\section{Methods and Materials}

\subsection{Sampling Procedure}

Vegetable samples of onion (stem, root and control stem/root samples) are harvested in the morning and evenings for three days consecutively were purchased in farmlands located along River Jakara, Kano State. Consequently, vegetable sample of onions also harvested in River Watari (located Bichi LGA Kano with no industrial and domestic activities but little agricultural activities) in the morning and evening, purchased from farmer along proximate location of the River was used as control.

\subsection{Sampling Preparation and Extraction Procedure}

The sample of vegetables was taken to the laboratory to wash thoroughly with distilled water and later dried. A portion of each sample (previously washed with distilled water and dried) was slashed with knife and pounded in a mortar to paste of its solution by adding de-ionized water. It was soaked for a while before filtering, using whatman $0.45 \mu \mathrm{m}$ filter paper. Each filterate (containing $50 \mathrm{~cm}^{3}$ ) was treated with $50 \mathrm{~cm}^{3}$ of trichloromethane and di-ethylether inside a separatory funnel. Two layers of organic and aqueous solvent were formed after previously shaken for 5 minutes and kept standing on retort stand for 5 minutes to settle. The organic solvent was decanted and concentrated using sodium sulphate to extract the organic compound in each sample, it was then placed in a vial, labeled and refrigerated before proceeding to Gas Chromatography-Mass Spectrometer analysis (GC/MS) [3]. Same procedure was replicated for other samples.

\subsection{Analysis of the Organic Extracts by GC/MS}

The various organic pollutants in labeled vials were taken to NARICT LABORATORY, Zaria, Kaduna State, Nigeria for Gas chromatography/mass spectrometer analysis.

The Gas Chromatography-Mass Spectrometer-QP 2010 Plus Schimadzu Japan Model works on the principle of mixture injected get separated into individual substance when the machine is switched on. The gases are carried through a column with inert gas (such as Helium). As the separated substance emerges from the column opening, they flow into the mass spectrometer. The mass spectrometer identifies the component by mass (Mass/charge ratio) of the analyte molecules [7], [8] \& [9]. 


\section{Results}

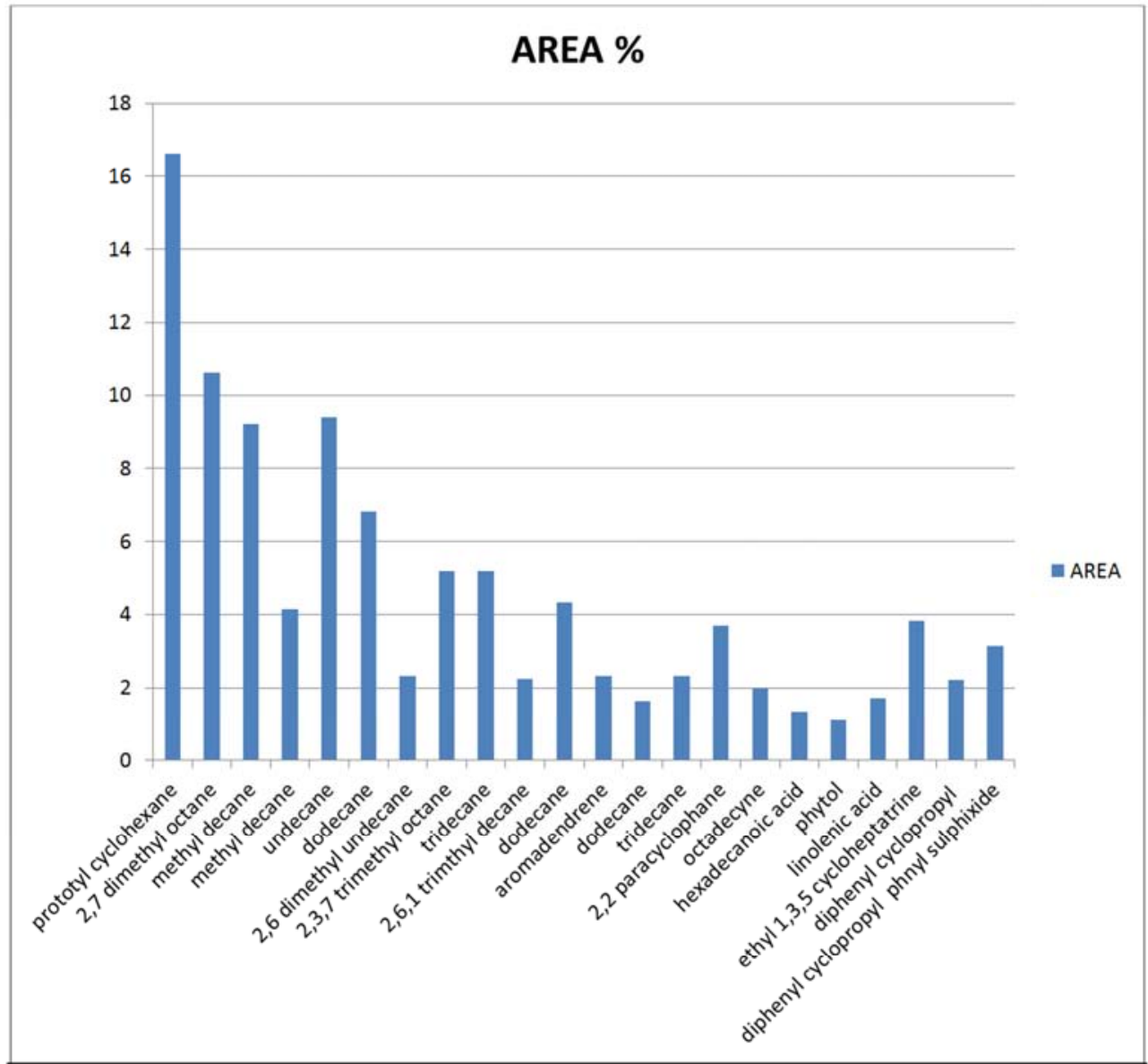

Figure 1. Bar chart representation of the Mean peak percentage (\%) values with organic pollutants detected in Onion root samples.

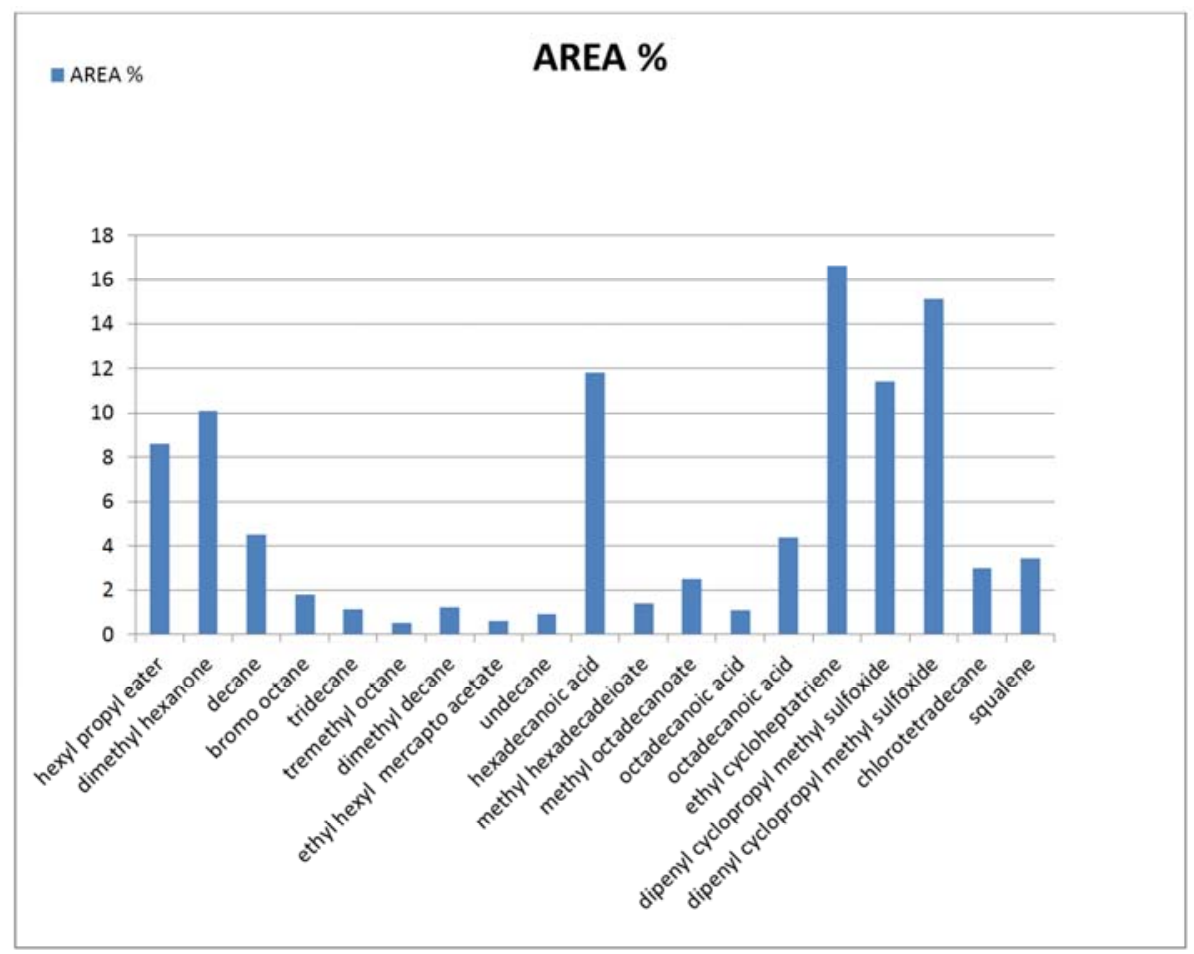

Figure 2. Bar chart representation of mean peak percentage (\%) values with organic pollutants detected in Onion shoots samples. 


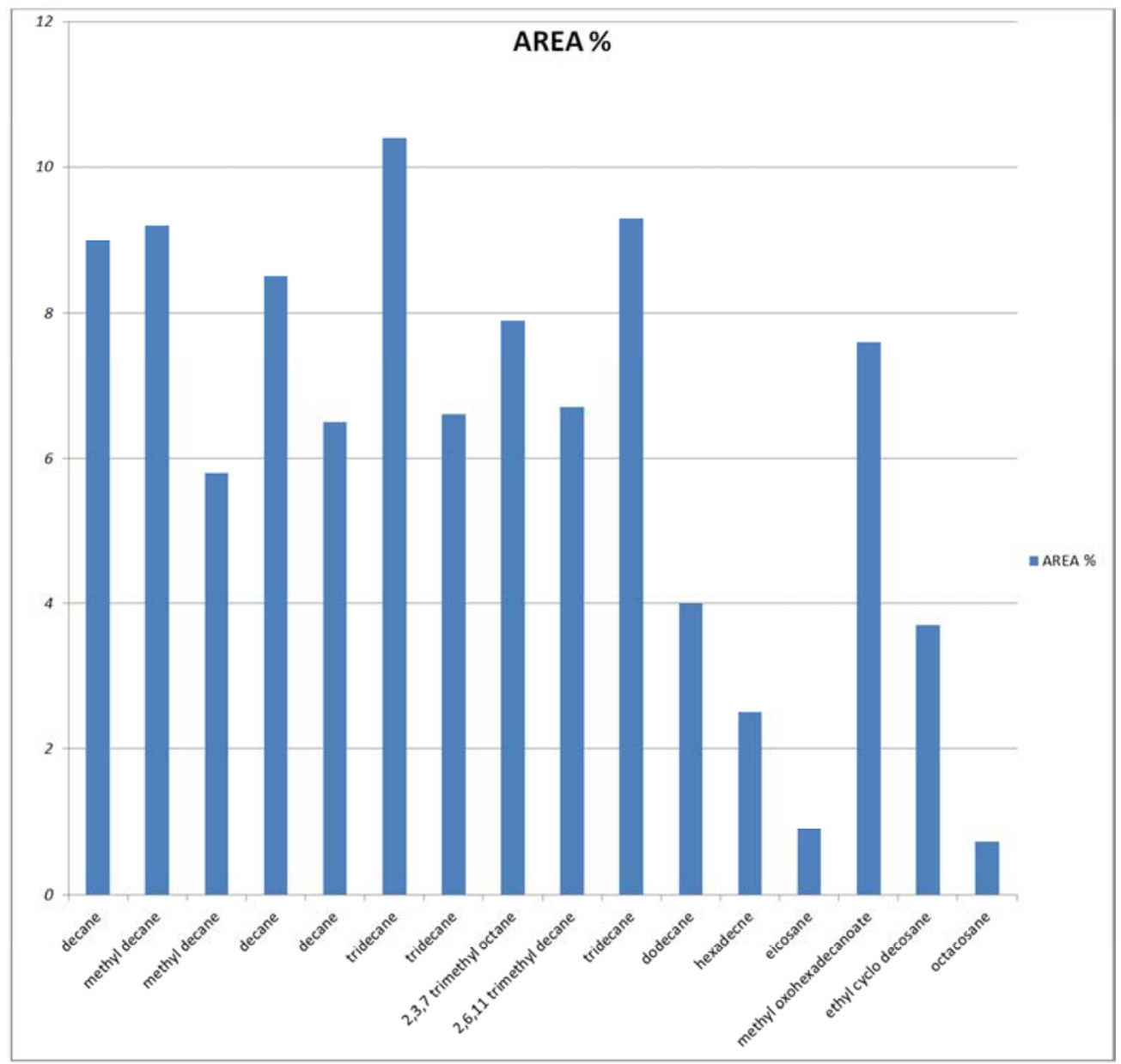

Figure 3. Bar chart representation of mean peak percentage (\%) values withorganic pollutants detected in Onion shoot samples. CONTROL.

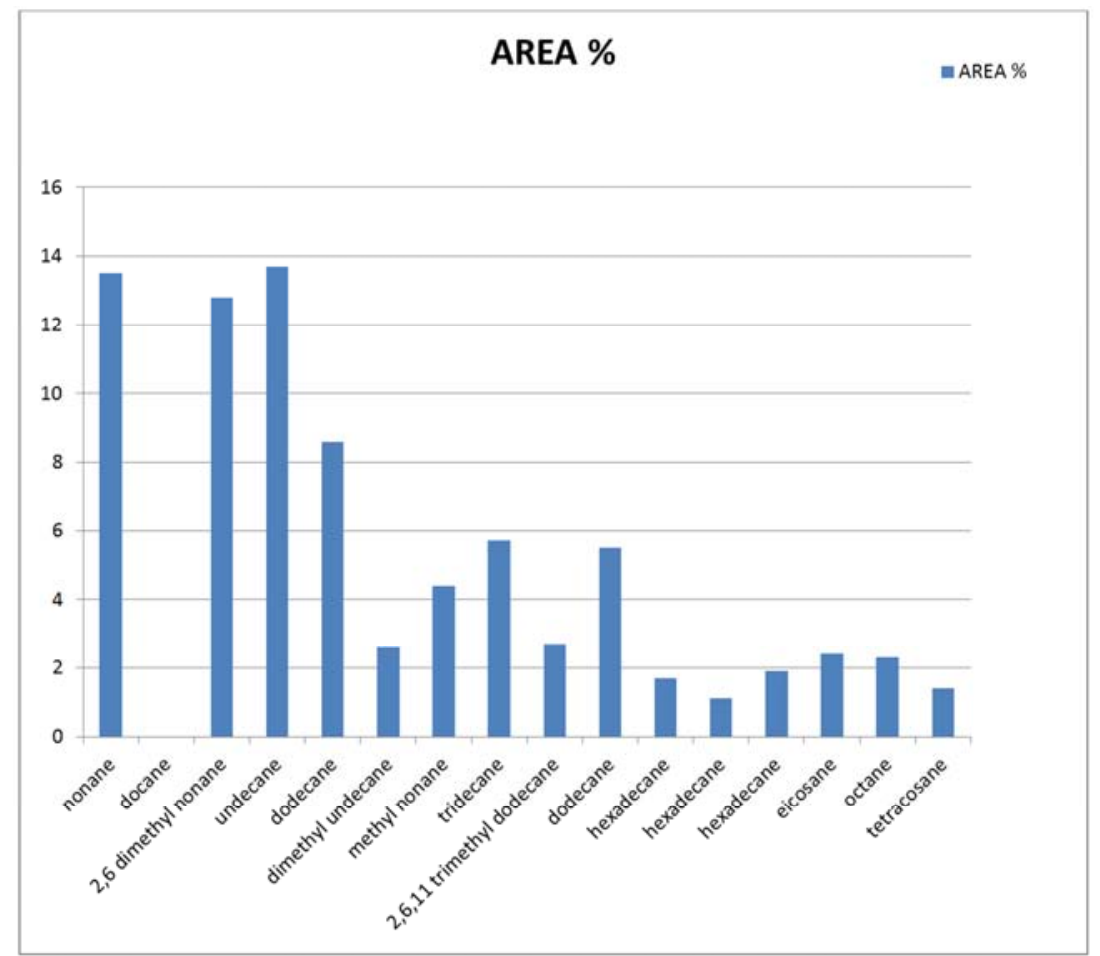

Figure 4. Bar chart representation of mean peak percentage (\%) values with organic pollutants detected in Onion root samples. CONTROL. 


\section{Discussion}

Table 1. Mean percentage (\%) values of organic pollutants detected in onion root, onion shoot, onion root (control) and onion shoot (control).

\begin{tabular}{|c|c|c|c|c|c|c|}
\hline SN & POLLUTANTS DETECTED & $\begin{array}{l}\text { ORGANIC } \\
\text { FORMULA }\end{array}$ & $\begin{array}{l}\text { ONION } \\
\text { ROOT \% }\end{array}$ & $\begin{array}{l}\text { ONION } \\
\text { SHOOT\% }\end{array}$ & $\begin{array}{l}\text { ONION ROOT \% } \\
\text { CONTROL }\end{array}$ & $\begin{array}{l}\text { ONION SHOOT \% } \\
\text { CONTROL }\end{array}$ \\
\hline 1 & $\begin{array}{l}\text { DECANE } \\
\text { UNDECANE } \\
\text { DODECANE } \\
\text { DIMETHYL UNDECANE } \\
\text { TRIMETHYL DECANE } \\
\text { AROMADENDRENE } \\
\text { PARACYCLOPHANE } \\
\text { OCTADECYNE } \\
\text { HEXADECANOIC ACID } \\
\text { HEXADECANE } \\
\text { PHYTOL } \\
\text { LINOLENIC ACID } \\
\text { ETHYLCYCLOHEPTATRIENE } \\
\text { DIPHENYL CYCLOPROPYL PHENYL } \\
\text { SULPHOXIDE } \\
\text { HEXYL PROPYL ESTER } \\
\text { DIMETHYL HEXANONE } \\
\text { BROMO OCTANE } \\
\text { ETHYL HEXYL MERCAPTO ACETATE } \\
\text { METHYL OCTADECANOATE } \\
\text { CHLOROTETRADECANE } \\
\text { SQUALENE }\end{array}$ & $\begin{array}{l}\mathrm{C}_{10} \mathrm{H}_{22} \\
\mathrm{C}_{11} \mathrm{H}_{24} \\
\mathrm{C}_{12} \mathrm{H}_{26} \\
\mathrm{C}_{13} \mathrm{H}_{28} \\
\mathrm{C}_{15} \mathrm{H}_{32} \\
\mathrm{C}_{15} \mathrm{H}_{24} \\
\mathrm{C}_{16} \mathrm{H}_{16} \\
\mathrm{C}_{18} \mathrm{H}_{32} \\
\mathrm{C}_{16} \mathrm{H}_{32} \mathrm{O}_{2} \\
\mathrm{C}_{16} \mathrm{H}_{34} \\
\mathrm{C}_{20} \mathrm{H}_{40} \mathrm{O} \\
\mathrm{C}_{18} \mathrm{H}_{30} \mathrm{O}_{2} \\
\mathrm{C}_{9} \mathrm{H}_{12} \\
\mathrm{C}_{22} \mathrm{H}_{20} \mathrm{O}_{5} \\
\mathrm{C}_{11} \mathrm{H}_{20} \mathrm{O}_{4} \\
\mathrm{C}_{8} \mathrm{H}_{16} \mathrm{O} \\
\mathrm{C}_{18} \mathrm{H}_{17} \mathrm{Br} \\
\mathrm{C}_{10} \mathrm{H}_{20} \mathrm{O}_{2} \mathrm{~S} \\
\mathrm{C}_{19} \mathrm{H}_{36} \mathrm{O}_{2} \\
\mathrm{C}_{14} \mathrm{H}_{29} \mathrm{Cl} \\
\mathrm{C}_{30} \mathrm{H}_{50}\end{array}$ & $\begin{array}{l}10.6 \\
9.2 \\
6.8 \\
2.3 \\
2.2 \\
2.3 \\
3.6 \\
1.9 \\
1.34 \\
\\
1.0 \\
1.7 \\
3.8\end{array}$ & $\begin{array}{l}16.6 \\
11.4 \\
8.6 \\
10.1 \\
1.8 \\
0.6 \\
2.5 \\
2.9 \\
3.4\end{array}$ & $\begin{array}{l}20.1 \\
12.8 \\
8.6 \\
2.6\end{array}$ & $\begin{array}{l}9.0 \\
9.2 \\
4.0 \\
10.4 \\
6.7\end{array}$ \\
\hline
\end{tabular}

Table 1; illustrated above depicts mean percentage (\%) values of organic pollutants detected in onion root samples, onion shoot samples, onion root control samples, onion shoot control samples. Twenty two (22) organic pollutants were detected with their percentage values of the aforementioned samples. They include decane, undecane, dodecane, dimethyl undecane, trimethyldecane, aromadendrene, paracyclophane, octadecyne, hexadecanoic acid, hexadecane, phytol, linolenic acid, ethyl cycloheptatriene, diphenyl cyclopropyl phenyl sulphoxide, hexyl propyl ester, dimethyl hexanone, bromo octane, ethyl hexyl mercapto acetate, methyl octadecanoate, chlorotetradecane, squalene and octacosane.

The lowest organic pollutants percentage value discovered was for ethyl hexyl mercapto acetate $(0.6 \%)$ and the highest organic pollutants percentage value discovered was for decane which is $20.1 \%$.

Nine (9) classes of organic groups were discovered with their various percentage values, they include alkane (decane, undecane, dodecane, dimethyl undecane, trimethyldecane), alkyne (octadecyne,aromadendrene), arene (paracyclophane), alkanol (phytol), haloalkane (bromo octane, chlorotetradecane), fatty acid (hexadecanoic acid, linolenic acid), alkanoate (hexyl propyl ester, methyl octadecanoate), ketone (dimethyl hexanone), organosulphur (ethyl hexyl mercapto acetate, diphenyl cyclopropyl phenyl sulphoxide).

The Onion root samples were analyzed and six (6) groups of organic pollutants were detected with various percentage values. They include alkane (decane $10.6 \%$, undecane $9.2 \%$, dimethyl undecane, $2.3 \%$, trimethyldecane $2.2 \%$ ); alkyne (octadecyne, 1.9\%); arene (aromadendrene, 2.3\%); alkanol (phytol, 1.0\%); fatty acid (hexadecanoic acid, 1.34\%, linolenic acid, 1.7\%); organosulphur (diphenyl cyclo propyl phenyl sulphoxide, $3.1 \%$ ).

The Onion shoot sample was also analyzed and five groups of organic pollutants were detected with various percentage values. They include alkane (dimethyl octane, $4.5 \%$, methyl decane, $0.9 \%$;), alkanoate (hexyl propyl ester, $8.6 \%$; methyl octadecanoate, $2.5 \%$ ); alkanone (dimethyl hexanone, 10.1\%); organosulphur (ethyl hexyl mercapto acetate, $0.6 \%$; diphenyl cyclopropyl phenyl sulphoxide, $11.4 \%$ ); haloalkane (bromo octane, 1.8\%; chlorotetradecane, $2.9 \%)$.

While the onion control samples (collected from a garden without activity) analyzed, gave one group of organic pollutants that is alkane group, they include docane $(9.0 \%$, $20.1 \%)$, methyl docane $(9.2 \%, 12.8 \%)$, dodecane $(4.0 \%$, $8.6 \%)$, trimethylundecane $(10.4 \%, 2.6 \%)$, octacosane $(2.5 \%$, $1.4 \%)$ and hexadecane $(0.7 \%, 1.7 \%)$ for onion shoot control samples and onion root control samples respectively [1], [9] $\&[11]$.

\section{Conclusion}

The inference reveals that six and five organic groups (onion root and onion shoot samples respectively) of various organic pollutants with their peculiar toxicity were examined and detected while the control samples (onion shoot and onion root samples) gave only a group of organic pollutant (alkane group for control sample of onion root and shoot) whose toxicity is tremendously minimum compared to other group of organic pollutants discovered. The result of this study indicates that all the samples collected, examined and analyzed for onions (with exception of control samples) have percentage (\%) values greater than threshold level recommended by World Health 
Organization (WHO) and National Environmental Standards and Regulations Enforcement Agency (NESREA). This state that human exposure present (for haloalkane, organosulphur among others) at level greater or equal to $0.1 \%$ is identified as probable, possible or confirmed human carcinogen by international agency for research on cancer (IARC). Pertaining to control samples predominantly alkane group, the United State Environmental Protection Agency (USEPA) listed alkane as a non- hazardous pollutant with a relatively short half-life, not expected to bioaccumulate [3], [10] \& [12].

\section{References}

[1] Abdulmajeed O. L and Abdulraham A. A (2011): Analysis of Heavy Metals Found in Vegetable from some Cultivated Irrigated Gardens in Kano Metropolis, Nigeria. Journal of Environmental chemistry and ecotoxicology. Vol 3(6) pp. 142148 .

[2] Akan J.C., Abdulrahman, F.I. Tijani M. and Chellube, Z. (2011): Determination of Pesticides in Extra Virgin and Emir Olive Oil obtained from Maiduguri Metropolis, Borno state. Conference proceedings of $34^{\text {th }}$ international conference workshop and exhibition of chemical society tagged 'Kwara2011'. Pp. 630-635.

[3] A. O. A. C., (2014):Association of Official Analytical Chemists, Official Methods of Analysis $14^{\text {th }}$ edition Washington D.C.

[4] Baker, H. G.,(2010): Plant and Civilization. $3^{\text {rd }}$ edition. Wadsworth Publishing Company Inc. California.pp.86.
[5] Claeys, A. and Salma, T. (2011): Determination of pesiticide residue in Fruit of Nawabshah District, Sindh, Pakistan, Pak. J. Bot 43 (2):1133-1139.

[6] Gushit A., Bente P. and Muazu H. (2003): Monitoring of herbicide residues and other organic pollutants in River Benue.Unpublished M.Sc thesis submitted to Ahmadu Bello University Zaria.

[7] Jayashree, R and N. Vasudevan (2007): Effect of Poisioning Caused by the Pesticides in Northern Ghana. Int J. Environ. Sci Tech. 4(20).203-210.

[8] Labunska I., Stringer R., Santillo D. and Stephenson A.(1998): Identification and Environmental significant of organic pollutants found in industrial wastewater and river sediments associated with Dow Quimica Company, Guaruja, SP, Brazil. Greepeace Research Laboratory. Pp. 1-9, Access at http://archive.greenpeace.org/toxic/reports/rhone.pdf.

[9] Oliver -Bever, B (2014): Medicinal Plants in Tropical West Africa. Cambridge, pp. 123-125.

[10] Sofowora, A. (1993): Medicinal plant in and Traditional Medicine in Africa. John Wiley and Sons limited. Chinchester, pp.135-153.

[11] Timothy, O and Idu, M., (2014): Preliminary phytochemical and in vitro anti-microbial properties of acqueous and methanolextracts of olive leaf. Int. J. Med. Arom. Plants. 1(3). 184-188.

[12] World Health Organization (2003): The value of plant used in traditional medicine for drug discovery. Environmental Health Perspectives 109:69-75. 